\title{
Osteoblast-conditioned media stimulate membrane vesicle shedding in prostate cancer cells
}

\author{
DANILO MILLIMAGGI ${ }^{1}$, CLAUDIO FESTUCCIA ${ }^{1}$, ADRIANO ANGELUCCI $^{2}$, \\ SANDRA D'ASCENZO ${ }^{1}$, NADIA RUCCI ${ }^{1}$, SILVIO FLATI $^{1}$, MAURO BOLOGNA $^{3}$, \\ ANNA TETI $^{1}$, ANTONIO PAVAN ${ }^{1}$ and VINCENZA DOLO ${ }^{1}$ \\ Departments of ${ }^{1}$ Experimental Medicine, ${ }^{2}$ Surgery, and ${ }^{3}$ Basic and Applied Biology, \\ University of L'Aquila, 67100 L'Aquila, Italy
}

Received July 27, 2005; Accepted September 1, 2005

\begin{abstract}
Although it has been shown that the cross-talk between osteoblasts and tumor cells stimulates proliferation and invasion of prostate carcinoma (PCa) cells, the molecular mechanisms underlying this event are largely unknown. In this study, we demonstrated that the PCa cells, PC3, derived from bone metastasis, undergo changes of their invasive capability if grown in the presence of osteoblast-derived conditioned media (OBCM). Specifically, they were able to organize tridimensional structures in Matrigel, such as large branching colonies, tube-like structures and clusters of proliferating cells, after treatment. At the ultrastructural level, we observed that PC3 cells grown in the presence of OBCM presented an increment of membrane activity with a blast of shed membrane vesicles from the cell surface. After $6 \mathrm{~h}$ of incubation, protein content was approximately 5-fold more elevated in vesicles isolated from PC3 cells cultured in OBCM than in unstimulated cultures. Gelatin zymography of vesicles collected from OBCM-treated PC3 cells showed an increment of lytic bands of MMP family members identified as proenzymatic and active forms of gelatinase A (MMP-2) and gelatinase B (MMP-9). By casein-plasminogen zymography, this latter culture also presented an elevated level of highmolecular weight urokinase plasminogen activator (HMWuPA). Purified vesicles from OBCM-treated PC3 cells incubated with Matrigel cleaved its components more efficiently than vesicles from untreated PC3 cells. Collectively, these findings indicate that osteoblasts produce factor/s able to modify the invasive capability of prostate cancer cells, increasing the amount of shed vesicles and of their associated lytic enzymes.
\end{abstract}

Correspondence to: Professor Vincenza Dolo, Dipartimento di Medicina Sperimentale, Università di L'Aquila, Via Vetoio-Coppito 2, 67100 L'Aquila, Italy

E-mail: dolo@univaq.it

Key words: prostate cancer, shed membrane vesicles, osteoblasts, metalloproteinases

\section{Introduction}

Prostate Cancer (PCa) metastasizes to bone with high frequency producing osteoblastic lesions. Several authors have demonstrated that PCa metastatization to bone is mainly dependent on the peculiar characteristics of the target organ. Following haematogenous dissemination, PCa cells are able to form a synergistic relationship with bone environment, creating favorable conditions for their development and growth (1). Since bone is continuously remodelled through the action of osteoblasts and osteoclasts, its microenvironment is particularly rich in growth factors (2). Many of these factors, such as insulin-like growth factors, have a proliferative effect on PCa cells, driving the initial phase of tumor implantation. At the same time, tumors reaching a critical mass, may release additional factors that determine an aberrant response by bone cells.

Increasing evidence suggests that the modulation of protease secretion by extracellular signals may play a key role in determining the ability of tumor cells to 'seed' in a particular target organ. Among the principal classes of matrix degrading proteases, metalloproteases (MMPs), a family of multidomain zinc-containing neutral endopeptidases, and plasminogen activators are involved in $\mathrm{PCa}$ progression. Specifically, PCa progression is associated with the expression of elevated levels of MMP-2 and MMP-9 $(3,4)$. Moreover, the MMP-2 and MMP-9 detected in plasma from PCa patients could be important for diagnosis and prognosis of malignant progression (5). A causal role of MMPs in PCa metastasis formation is clearly demonstrated by the effective action of MMP inhibitors in reducing experimental bone metastasis in vivo (6).

The plasmin cascade driven by urokinase (UPA) and tissue plasminogen activator (tPA) was shown also to be associated with extracellular matrix (ECM) degradation (7). In detail, uPA, through its protease activity, converts plasminogen to plasmin, a serine protease capable of activating a cascade of extracellular proteases at focal sites adjacent to the cell surface, thus determining the local degradation of the ECM. The uPA expression and uPA-mediated extracellular matrix degradation by $\mathrm{PCa}$ correlates with their metastatic behaviour (8), and elevated uPA levels in the serum from PCa patients correlate with increased numbers of bone metastases (9). 
The interplay between tumor and host cells is mediated by multiple mechanisms, including direct cell-cell contact and secretion of cytokines and bioactive molecules released both as soluble factors or as components of shed membrane vesicles.

Shedding of membrane vesicles from the cell surface is widely observed in normal and tumor cells in vivo and in vitro (10). In normal cells, the process appears to be tightly regulated, since only a limited number of vesicles is shed from defined areas of the plasma membrane in response to specific stimuli (11). In contrast, vesicle shedding by tumor cells is a largely deregulated process, since numerous vesicles are constitutively shed from the entire cell surface $(12,13)$.

Shed membrane vesicles carry bioactive molecules that modulate cell functions in an autocrine and paracrine manner, ultimately affecting several aspects of tumor malignancy. Tumor-shed vesicles can affect the host immune response $(14,15)$, promote tumor invasiveness and metastasis $(13,16,17)$, confer drug resistance (18) and, as recently described, carry angiogenic stimuli $(19,20)$.

In the present study, we explored further the regulation of this machinery by combined morphological/biochemical approaches and by analysis of proteases present in vesicles shed from invasive cells after stimulation with factors present in osteoblast-derived conditioned media. We demonstrated that osteoblasts are able to produce factor/s that modify the invasive capability of prostate cancer cells which increase the shed of membrane vesicle-associated lytic enzymes.

\section{Materials and methods}

Cell cultures. The human prostatic cell line, PC3, was obtained from ATCC (Rockville, MD) and was cultured in 10\% FCSsupplemented Dulbecco's modified Eagle's medium (DMEM).

Primary cultures of osteoblasts (OB) were prepared from calvaria of 7-9 day old CD1 mice. Briefly, calvaria were removed, cleaned free from soft tissues, and digested 3 times with $1 \mathrm{mg} / \mathrm{ml}$ Chlostridium histolyticum type IV collagenase and $0.25 \%$ trypsin, for $20 \mathrm{~min}$ at $37^{\circ} \mathrm{C}$, with gentle agitation. Cells from the second and third digestion were plated and grown to confluence in DMEM plus $10 \%$ FCS. At confluence, cells were trypsinized by standard procedure and plated according to the experimental protocol. These cells expressed the osteoblast markers, alkaline phosphatase (ALP), Runx2 (runt-related transcription factor 2), PTH/PTHrP receptor, type I collagen and osteocalcin (21).

Eighteen-hour conditioned media (OBCM) with $1 \%$ FCS were collected from proliferating subconfluent OB cultures, diluted 1:3 with DMEM and then added to PC3 cell cultures for different treatment times.

Isolation of membrane vesicles from cell-conditioned medium. Vesicles were prepared as described (13). Conditioned media, obtained as specified, were centrifuged at $600 \mathrm{~g}$ for $15 \mathrm{~min}$ and at $1500 \mathrm{~g}$ for $30 \mathrm{~min}$ to remove cells and large debris. Supernatants were then centrifuged at $100.000 \mathrm{~g}$ for $1 \mathrm{~h}$ at $4^{\circ} \mathrm{C}$. Pelleted vesicles were resuspended in phosphate-buffered saline (PBS), $\mathrm{pH}$ 7.4. Vesicles were quantified based on the measurement of vesicle-associated protein levels, using the method of Bradford (BioRad, Milan, Italy), with BSA (Sigma, St. Louis, MO) as the standard.
Electron microscopy. Ultrastructural morphology of cells, grown in a double layer of Matrigel and seeded on Matrigelcoated filters, was analyzed by transmission electron microscopy (TEM). TEM analysis was performed using a standard technique. Briefly, cells were fixed with $2 \%$ glutaraldehyde and post-fixed with $1 \% \mathrm{OsO}_{4}$, dehydrated with ethanol and embedded in Epon 812. Samples were then sectioned, poststained with uranyl acetate and lead citrate, and examined under an electron microscope (Philips CM10, Eindhoven, The Netherlands).

For analysis of ultrastructural morphology of the membrane vesicles shed by PC3 cells, the ultracentrifugation pellet, which contained the membrane vesicles, was resuspended in PBS and then applied to collodion-coated grids. After washing, the membrane vesicles were negatively stained with $1 \%$ phosphotungstic acid, brought to $\mathrm{pH} 7.0$ with $\mathrm{NaOH}$, and examined by transmission electron microscopy (17).

Invasion assays. The ability of cells to migrate across a Matrigel barrier (invasion) was determined by the modified Boyden-chamber method (22). Briefly, tumor cells $\left(1 \times 10^{5}\right.$ per chamber) were added to PVP-free, $8 \mu \mathrm{m}$ polycarbonate filters (Nucleopore, Concorezzo, Milan, Italy) coated with $50 \mu \mathrm{l}$ of $12.5 \mu \mathrm{g} / \mathrm{ml}$ Matrigel and incubated with DMEM containing $0.1 \% \mathrm{BSA}$ for $6 \mathrm{~h}$ at $37^{\circ} \mathrm{C}$. OBCMs were used as chemo-attractants, and $0.3 \%$ FCS was used as basal control. Filters were removed from the chambers and stained by $0.1 \%$ toluidine blue. Cells were counted at a magnification $\mathrm{x} 400$, and the mean numbers of cells per field in 5 random fields were recorded. Duplicate filters were used, and the experiments were repeated 3 times.

Substrate zymograms for protease activities. Conditioned media and isolated vesicles were electrophoresed in nonreducing SDS-PAGE conditions in gel co-polymerized with $0.1 \%$ gelatin for gelatinase activities and with $0.1 \%$ casein plus $15 \mu \mathrm{g} / \mathrm{ml}$ plasminogen for plasminogen-activator (PA) activities. Following electrophoresis, the gels were washed 3 times with $50 \mathrm{mM}$ Tris- $\mathrm{HCl}$ ( $\mathrm{pH} 7.4$ ) containing $2 \%$ Triton $\mathrm{X}-100$ for $15 \mathrm{~min}$ and 3 times with $50 \mathrm{mM}$ Tris- $\mathrm{HCl}(\mathrm{pH} 7.4)$ for $15 \mathrm{~min}$ at room temperature with shaking to remove SDS. Gels were then incubated in Tris- $\mathrm{HCl}(\mathrm{pH} 7.4)$ containing $10 \mathrm{mM} \mathrm{CaCl}_{2}, 200 \mathrm{mM} \mathrm{NaCl}$ (gelatinases) or without salts (PA activities) at $37^{\circ} \mathrm{C}$ in a Dubnoff shaker. The incubation time was usually $16 \mathrm{~h}$. Control gels without plasminogen were also used to verify PA activity. The gels were fixed and stained with $0.1 \%$ Coomassie blue solution. Enzyme-digested regions were identified as white bands against a blue background. Protein concentrations were measured using a BioRad (Hercules, CA) protein assay.

Reverse zymograms for tissue inhibitors of metalloproteinases (TIMPs). Concentrated supernatants containing $20 \mu \mathrm{g}$ of proteins [conditioned media concentrated 20 -fold by Centricon (Amicon, Beverly, MA), with $10 \mathrm{kDa}$ m.w. cut-off], were analyzed by $14 \%$ SDS-PAGE containing $0.1 \%$ casein and $30 \%(\mathrm{v} / \mathrm{v})$ serum-free supernatants from the MDA-MB-231 human breast cancer cell line. This cell line expresses a single $53 \mathrm{kDa}$ band of EDTA-inhibitable caseinolytic activity in zymograms (MMP-3). Gels were processed as described above, 


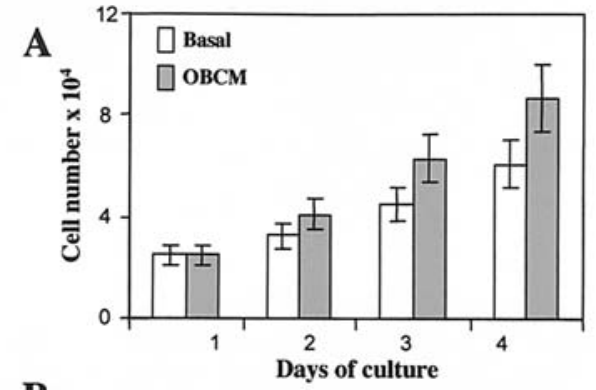

B

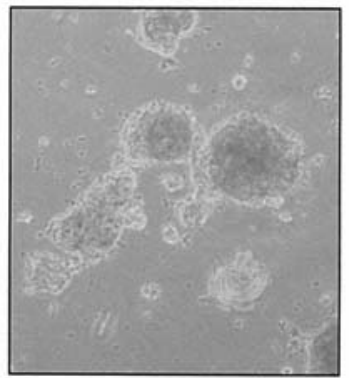

Basal

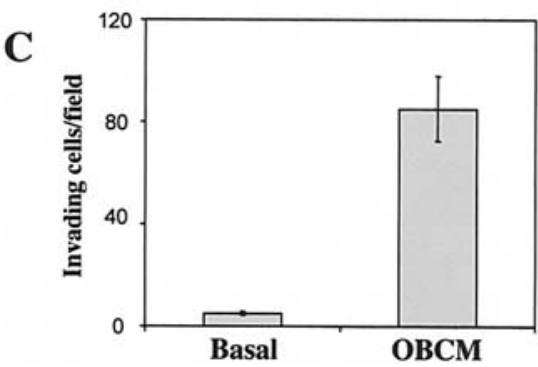

Figure 1. Proliferation and invasion in OBCM-stimulated PC3 cells. (A) Proliferation rate of unstimulated and OBCM-stimulated PC3 cells. (B) PC3 cell growth in Matrigel. Cells plated and grown in the presence of OBCM show branching colonies while, in basal, only rounded colonies are seen. (C) Chemo-invasion analysis of Matrigel-coated filters. These experiments were performed as described in Materials and methods. This figure is representative of 3 independent experiments. Each data set represent mean \pm standard deviation (SD) of triplicates. A, $\mathrm{p}<0.05$ for $\mathrm{OBCM}$ versus basal only at 3 and 4 days of culture; $\mathrm{C}, \mathrm{p}<0.001$.

except for a 72-h incubation in the collagenase buffer. Dark stained bands of 28 and $21 \mathrm{kDa}$ m.w. were identified as inhibitor bands of TIMP-1 and TIMP-2, respectively.

Matrix degradation assay. Membrane vesicles $(20 \mu \mathrm{g}$ of protein) from unstimulated and OBCM-stimulated PC3 cells were incubated with $40 \mu \mathrm{g}$ of Matrigel in activation buffer (Tris- $\mathrm{HCl} 50 \mathrm{mM}, 5 \mathrm{mM} \mathrm{CaCl}{ }_{2}$ and $150 \mu \mathrm{g} / \mathrm{ml}$ human plasminogen $\mathrm{pH} 7.5$ ) at $37^{\circ} \mathrm{C}$ for $2 \mathrm{~h}$. Inhibition of Matrigel degradation was performed using 1,10 phenanthroline $(1,10$ pht) $(5 \mathrm{mM})$ and p-aminobenzamidine $(\mathrm{pABM})(50 \mathrm{mM})$ to block MMP and uPA activities, respectively. Reactions were stopped with sample buffer and, after boiling, samples were analyzed in $7.5 \%$ SDS-PAGE. Substrate cleavage products were visualized by staining with Coomassie Blue. Densitometric analysis was performed and the data are given as mean \pm SD of triplicate independent experiments.

Statistical analysis. Results are expressed as mean \pm SD of at least three independent experiments. Demonstration of significant differences among means was performed by
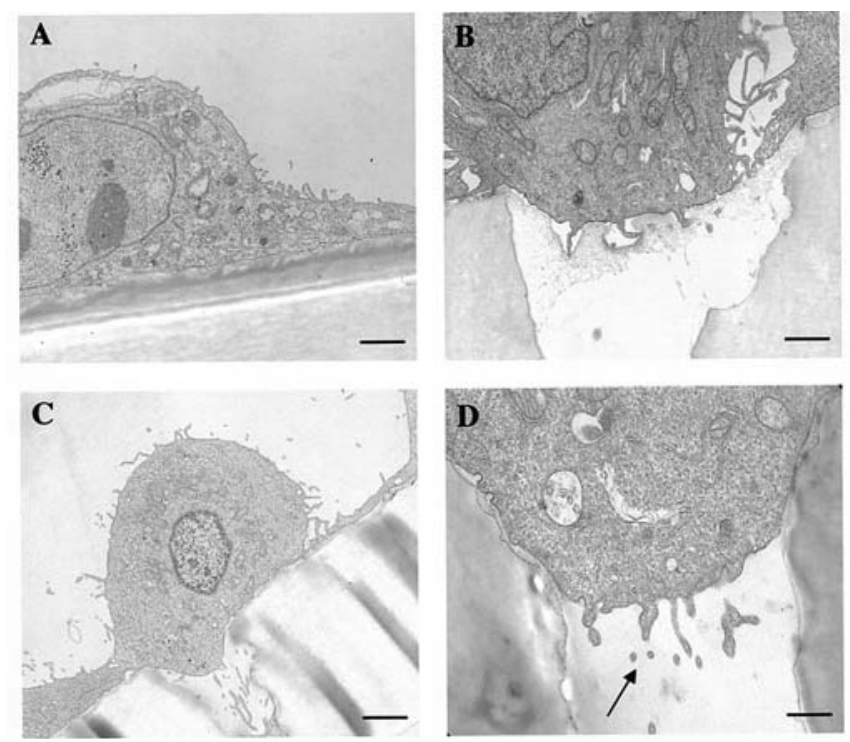

Figure 2. Ultrastructural analysis of PC3 cells seeded on Matrigel-coated filters. (A) The first step of cell adesion to Matrigel. (B) The initial matrix degradation is carried out by pseudopodia. (C) After Matrigel degradation (inside pores), the vesicle shedding phenomenon started; with a high magnification, the membrane vesicle shedding in the extracellular space is clearly visible (D). Scale bars indicate (A) $2.7 \mu \mathrm{m}$, (B) $2 \mu \mathrm{m}$, (C) $2.6 \mu \mathrm{m}$ and (D) $1 \mu \mathrm{m}$

Student's t test considering 0.05 as the threshold value of $\mathrm{P}$. All statistical analyses were performed using Kaleidagraph 3.6 (Synergy Software).

\section{Results}

Proliferation and invasion in OBCM-stimulated PC3 cells. In a first series of experiments, we evaluated the effect of OBCM on the proliferative ability of PC 3 cells. Cells were cultured for 4 days in the presence of OBCM and counts were performed each day, confronting results with the number of cells cultured in basal conditions (Fig. 1A). The stimulation of PC3 proliferation was statistically evident after the third day of culture in the presence of OBCM and about $25 \%$ more cells were present after 4 days in relation to the control.

Cell growth in Matrigel has been extensively used to study the colony-forming ability of transformed cells and to identify invasive phenotype of new tumor cell lines (22). Therefore, we verified the ability of PC3 cells to form branching colonies when grown in a double layer of Matrigel. OBCM-treated PC3 cells acquired invasive phenotype organizing 3D structures, such as large branching colonies, tube-like structures and clusters of proliferating cells (Fig. 1B). In order to test the invasive ability of $\mathrm{PC} 3$ cells, we performed a Boyden chamber assay. The presence of OBCM induced an increase in the number of invaded PC3 cells about 8-fold compared to an assay performed in $0.3 \%$ serum medium (Fig. 1C).

In order to understand the site and the mechanisms of ECM degradation, a transmission electron microscopic analysis of the matrigel-coated filter with seeded PC3 cells was performed. At the ultrastructural level, we initially observed complete cell adhesion to the Matrigel (Fig. 2A). Subsequently, long membrane protrusions, invadopodia-like structures, extending into the Matrigel were observed (Fig. 2B). In these sites, the beginning of the substrate degradation performed by the 


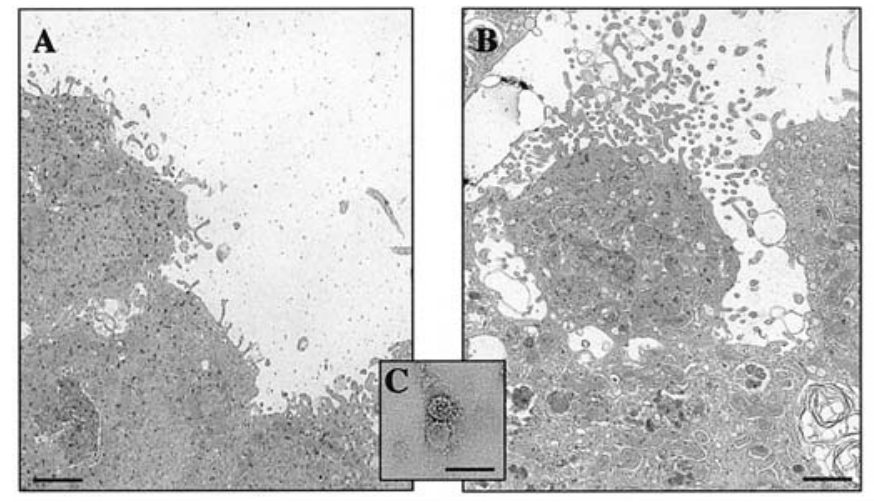

Figure 3. Ultrastructural analysis of the vesicle shedding phenomenon. (A) Transmission electron microscopic pictures of unstimulated PC3 cells grown in Matrigel and (B) OBCM-stimulated cells. The vesicle shedding process is more evident in the treated cells than in the control. (C) Morphological picture of isolated membrane vesicles $(400 \mathrm{~nm})$ with negative staining. Scale bars indicate (A) $3 \mu \mathrm{m}$, (B) $2.6 \mu \mathrm{m}$, (C) $800 \mathrm{~nm}$.

invadopodia was clearly seen. Moreover, after the Matrigel degradation, we identified a release of small membrane vesicles at the site of ECM degradation (Fig. 2C), and inside the filter pore (Fig. 2D, arrow).

OBCM stimulates vesicle shedding in PC3 cells. The OBCMtreated PC3 cells grown in a double layer of Matrigel were also collected, fixed and embedded to obtain ultrastructural morphological data. Fig. 3 demonstrates the morphological changes of PC3 cells grown in the presence of OBCM. Osteoblast-conditioned PC3 cells showed an increment of membrane activity with a blast of shed vesicles (Fig. 3B) released from the cell plasma membrane into the extracellular area in relation to unstimulated cells (Fig. 3A). In addition, we observed a decrement of cell-cell interactions with less desmosomes and cell junctions (data not shown). The conditioned media of PC3 cells cultured with OBCM or in basal conditions were ultracentrifuged and the presence of membrane vesicles in the pellet was analyzed by ultrastructural analysis with a negative staining under electron microscope. Membrane vesicles, morphologically similar to those produced by other tumor cells (17), were observed. Vesicles presented a roughly spherical shape with heterogeneous size ranging from 300 to $600 \mathrm{~nm}$ and an intact membrane (Fig. 3C). Isolated vesicles derived from unstimulated and OBCM-stimulated PC3 cell cultures were collected after 3,6 and $18 \mathrm{~h}$ of treatment. We measured vesicle amounts by total protein assay and observed that vesicle-derived protein was more elevated in OBCMstimulated PC3 medium ( $8 \mu \mathrm{g}$ pt $/ 10 \times 10^{6}$ cells) in relation to unstimulated PC3 medium ( $1.6 \mu \mathrm{g}$ pt $/ 10 \times 10^{6}$ cells $)$. The maximum effect was evident after $6 \mathrm{~h}$ of treatment, showing that $\mathrm{OBCM}$ was able to stimulate vesicle shedding approximately 5 -fold in a short time.

Vesicle-associated proteolytic activities. Our previous results showed that, due to their protease content, vesicle shedding is associated with the invasive phenotype of cells. Thus, we evaluated the protease expression in vesicles collected from the media of unstimulated and OBCM-stimulated PC3 cells.

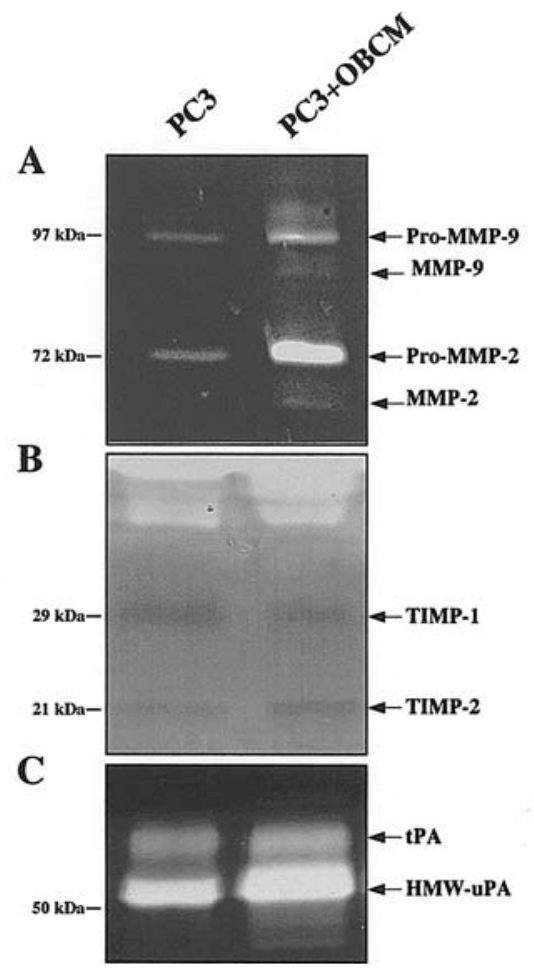

Figure 4. Vesicle-associated lytic enzymes from unstimulated and OBCMstimulated PC3 cells. (A) Gelatin zymography shows the presence of MMP-9 (97 kDa pro-form and $82 \mathrm{kDa}$ active form) and MMP-2 (72 kDa pro-form and $55-58 \mathrm{kDa}$ active-form). (B) Reverse zymography reveals the presence of TIMP-1 (29 kDa) and TIMP-2 (21 kDa). (C) Casein zymography evidentiates the presence of uPA (HMW-uPA of $50 \mathrm{kDa}$ ) and tPA (70 kDa). Vesicles were collected and processed as described in Materials and methods.

The presence of matrix-degrading proteinases was analyzed by gelatin zymography (Fig. 4A). Lytic bands corresponding to pro-MMP-9 and pro-MMP-2 were observed in both samples, but the exposure to OBCM increased the content of vesicle-associated proMMPs by 7 - and 10-fold respectively. Concurrently, we found the active forms of MMP-9 (82 kDa) and MMP-2 (55 kDa). The presence of the physiological MMP inhibitors, TIMP-1 and TIMP-2, was examined by reverse zymography (Fig. 4B). Both TIMP-1 and TIMP-2 were clearly detectable in both samples. The expression of TIMP-1, a natural inhibitor of MMP-9, was inhibited by approximately $30 \%$ by OBCM treatment and the MMP-9: TIMP-1 ratio was increased by approximately 4-fold. The presence of TIMP-2, a natural inhibitor of MMP-2, was increased by approximately 2-fold. Consequently, the MMP-2: TIMP-2 ratio was decreased by approximately 5 -fold.

Casein-plasminogen zymography was used to verify the presence of vesicle-associated uPA. Both untreated and OBCM-treated PC3 cells showed a caseinolytic band with an apparent molecular mass of approximately $50 \mathrm{kDa}$ and an increment in lytic activity of vesicles shed by OBCM-treated PC3 cells of approximately 2-fold (Fig. 4C).

We then analysed the Matrigel degradation by vesicles in SDS-PAGE and evaluated, by densitometric analysis, the expression of the two main bands generated by Matrigel with an apparent molecular weight of approximately $200 \mathrm{kDa}$. Fig. 5 demonstrates that OBCM-induced vesicles were able to degrade Matrigel with a higher efficiency than vesicles 


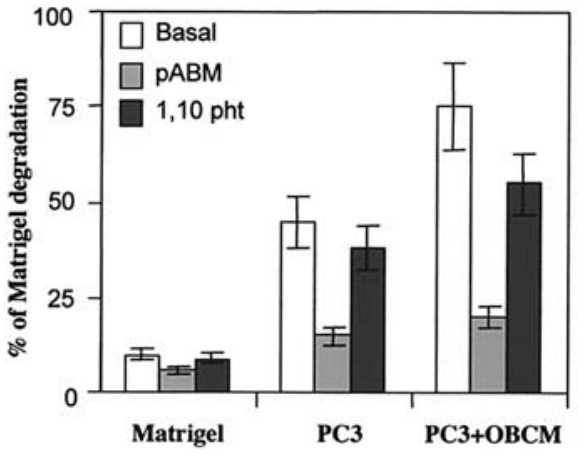

Figure 5. Matrigel degradation has been evaluated densitometrically as the loss rate of two high molecular weight forms of $>200 \mathrm{kDa}$ of the Matrigel preparation. Vesicles (20 $\mu \mathrm{g}$ of proteins) were incubated with $40 \mu \mathrm{g}$ of Matrigel for $2 \mathrm{~h}$ in $100 \mu \mathrm{l}$ of digestion buffer containing Tris- $\mathrm{HCl} 50 \mathrm{mM}$, $5 \mathrm{mM} \mathrm{CaCl}{ }_{2}$ and $150 \mu \mathrm{g} / \mathrm{ml}$ human plasminogen. Inhibition of Matrigel degradation was performed using 1,10 phenanthroline $(5 \mathrm{mM})$ and p-aminobenzamidine $(50 \mathrm{mM})$ to block MMP and uPA activities, respectively. Each column represents the percentage of undegraded Matrigel and data are given as mean $\pm \mathrm{SD}$ of triplicate determinations in 3 independent experiments. Statistical analysis included in the text.

usually expressed by PC3 cells $(\mathrm{p}<0.001)$. Matrigel degradation was inhibited by the use of serine- $(\mathrm{p}<0.01)$ and metalloprotease $(\mathrm{p}<0.05)$ inhibitors. The addition of $50 \mathrm{mM}$ p-aminobenzamidine (pABM) and $5 \mathrm{mM}$ 1,10-phenantroline reduced the substrate degradation percentage reverting, in the case of pABM, the amount of undigested Matrigel to almost basal conditions.

\section{Discussion}

To progress toward full malignancy, a cancer cell acquires changes that make it relatively independent from inhibitory signals present in the extracellular matrix. However, cancer cells are able to evolve forming new positive and dynamic interactions with the stroma throughout the disease process. Many of these interactions between the tumor cells and host tissue represent a violation of the normal tissue boundaries that physiologically prevent intermixing of cells from different tissues. As a consequence of the presence of tumor cells, a highly modified host microenvironment is produced in which a plethora of cytokines and bioactive molecules provide structural and functional cues for several steps of the tumorigenic and metastatic cascade. Rather than being a totally random dissemination process, tumours display a preferential spread to particular organs. Therefore, it is well known that breast, prostate, and lung cancer, which are the most common malignancies, often metastasise to bone.

This study provides the first evidence that the paracrine factors released by osteogenic cells modulate the membrane shedding from a bone-metastasis derived PCa cell line, PC3, increasing the protease-containing vesicles that may play an important role in $\mathrm{PCa}$ progression.

According to our previous results, OBCM stimulates the proliferation and Matrigel invasion of PC3 cells (23). The bone microenvironment may therefore represent a suitable secondary site of tumor growth in which complex dynamic relations between prostate cancer cells and normal cells occur. One of the cell activities that support this cross-talk could be the shedding of membrane vesicles from the tumor cell surface in extracellular areas.

The shedding of membrane vesicles from the cell plasma membrane is considered to be an additional mechanism of the turnover of membrane. It occurs in specific membrane portions in which selected molecules are concentrated (17). We previously reported that PC3 cells shed membrane vesicles and we demonstrated the important role played by vesicleassociated uPA in promoting prostate tumor progression (24). The ultrastructural analysis of PC3 cells grown on Matrigel shows a large amount of vesicles shed from the plasma membrane after OBCM stimulation compared to the unstimulated cells. The important role of vesicle-associated lytic enzymes in the degradation of ECM components has been well demonstrated (17).

In this study, considerable attention has been given to the role of matrix metalloproteinases, especially MMP-9, MMP-2, and UPA associated to shed vesicles. Vesicles shed by OBCMstimulated and unstimulated PC3 cells show qualitative and quantitative differences in the amount of proteolytic enzymes they carry. The presence of MMP-2 and MMP-9 was seen in both shed vesicle samples but, in PC3 OBCM-stimulated shed vesicles, a higher amount of pro-MMP-2 and pro-MMP-9 was found than in unstimulated shed vesicles. Moreover, the presence of active forms, MMP-2 and MMP-9, was evident.

The catalytic activity of gelatinases, MMP-9 and MMP-2, is tightly regulated at three levels: gene transcription, proenzyme activation and inhibition by specific tissue inhibitors (TIMPs), TIMP-1 and TIMP-2, respectively. The observed decrease in TIMP-1 level suggests that the gelatinolytic activity expressed by vesicles was dependent mainly on MMP-9. Thus, in our system, we observed that the MMP-9:TIMP-1 ratio significantly increased.

Although the MMP-2:TIMP-2 ratio is lower after OBCMtreatment, it should be considered that TIMP-2 collaborates with MT1-MMP for exposing cell surface-associated MMP-2 at the degradation site of the cells (25). However, several studies have shown that a high level of TIMP-2 correlates with a poor prognosis in many types of cancers (26). In fact, MMP-2 is activated by the formation of a molecular complex containing TIMP-2 that appears fundamental for the formation of the fully mature form of MMP-2 (27). For this reason the modest increase in TIMP-2 could not be associated with a decrease in MMP-2 activity. MMP-2 also seems to be activated by OBCM treatment.

uPA is another crucial component for the local invasion of tissue. This serine protease binds to its receptors (uPAR) in the plasma membrane and then interacts with serum plasminogen to generate plasmin, which in turn activates collagenases and metalloproteases, and stimulates production of uPA in a cyclic cascade reaction (28).

Both tissue (tPA, $70 \mathrm{kDa}$ ) and urokinase type plasminogen activator (uPA, $50 \mathrm{kDa}$ form) were found in vesicles. Even if no differences were seen in the level of tPA, the expression of UPA was more elevated in PC3 shed vesicles after OBCM stimulation. In our system, vesicle-associated uPA and MMPs were able to degrade ECM components as confirmed by ultrastructural and biochemical analyses. Transmission electron microscopy reveals that cell pseudopodia started the matrix degradation in sites adjacent to the cell and, subsequently, the 
vesicle shedding takes part in this process performing a distant proteolysis.

In summary, these findings demonstrate that OBCM is able to stimulate vesicle shedding and, at the same time, is able to increase the amount of vesicle-associated lytic enzymes. Since the activity of proteases is the initial step of tumor implantation in the target organ, we propose that the modulation of the shedding phenomenon by osteogenic factors could be a key event for understanding the bone tissue remodelling by prostate cancer and local growth in PCa metastasis.

\section{Acknowledgements}

This work was supported by grants from the Italian Ministry of University and Scientific and Technological Research (MURST) to A.P. and V.D; from F.I.R.B to A.P.

\section{References}

1. Mundy GR: Mechanisms of bone metastasis. Cancer 80: 1546-1556, 1997.

2. Hauschka PV, Mavrakos AE, Iafrati MD, Doleman SE and Klagsbrun M: Growth factors in bone matrix. Isolation of multiple types by affinity chromatography on heparinSepharose. J Biol Chem 261: 12665-12674, 1986.

3. Trudel D, Fradet Y, Meyer F, Harel F and Tetu B: Significance of MMP-2 expression in prostate cancer: an immunohistochemical study. Cancer Res 63: 8511-8515, 2003.

4. Assikis VJ, Do KA, Wen S, et al: Clinical and biomarker correlates of androgen-independent, locally aggressive prostate cancer with limited metastatic potential. Clin Cancer Res 10: 6770-6778, 2004

5. Morgia G, Falsaperla M, Malaponte G, Madonia M, Indelicato M, Travali S and Mazzarino MC: Matrix metalloproteinases as diagnostic (MMP-13) and prognostic (MMP-2, MMP-9) markers of prostate cancer. Urol Res 33: 44-50, 2005.

6. Bissell MJ, Le Beyec J and Anderson RL: Prostate cancer in bone: importance of context for inhibition of matrix metalloproteinases. J Natl Cancer Inst 94: 4-5, 2002.

7. Webber MM and Waghray A: Urokinase-mediated extracellular matrix degradation by human prostatic carcinoma cells and its inhibition by retinoic acid. Clin Cancer Res 1: 755-761, 1995.

8. Quax PH, de Bart AC, Schalken JA and Verheijen JH: Plasminogen activator and matrix metalloproteinase production and extracellular matrix degradation by rat prostate cancer cells in vitro: correlation with metastatic behaviour in vivo. Prostate 32: 196-204, 1997.

9. Hienert G, Kirchheimer JC, Christ G, Pfluger H and Binder BR: Plasma urokinase-type plasminogen activator correlates to bone scintigraphy in prostatic carcinoma. Eur Urol 15: 256-258, 1988.

10. Taylor DD and Black PH: Shedding of plasma membrane fragments. In: Developmental Biology. Edited by MS Plenum Press, New York, pp33-57, 1986.

11. Taraboletti G, D'Ascenzo S, Borsotti P, Giavazzi R, Pavan A and Dolo V: Shedding of the matrix metalloproteinases MMP-2, MMP-9, and MT1-MMP as membrane vesicle associated components by endothelial cells. Am J Pathol 160: 673-680, 2002 .
12. Dolo V, Adobati E, Canevari S, Picone MA and Vittorelli ML: Membrane vesicles shed into the extracellular medium by human breast carcinoma cells carry tumor-associated surface antigens. Clin Exp Metastasis 13: 277-286, 1995.

13. Dolo V, Ginestra A, Ghersi G, Nagase H and Vittorelli ML: Human breast carcinoma cells cultured in the presence of serum shed membrane vesicles rich in gelatinolytic activities. J Submicrosc Cytol Pathol 26: 173-180, 1994.

14. Albanese J, Meterissian S, Kontogiannea M, Dubreuil C, Hand A, Sorba $S$ and Dainiak N: Biologically active Fas antigen and its cognate ligand are expressed on plasma membrane-derived extracellular vesicles. Blood 91: 3862-3874, 1998.

15. Zitvogel L, Fernandez N, Lozier A, Wolfers J, Regnault A, Raposo G and Amigorena S: Dendritic cells or their exosomes are effective biotherapies of cancer. Eur J Cancer 35: S36-S38, 1999.

16. Dolo V, D'Ascenzo S, Violini S, et al: Matrix-degrading proteinases are shed in membrane vesicles by ovarian cancer cells in vivo and in vitro. Clin Exp Metastasis 17: 131-140, 1999.

17. Dolo V, Ginestra A, Cassara D, et al: Selective localization of matrix metalloproteinase 9, beta1 integrins, and human lymphocyte antigen class I molecules on membrane vesicles shed by 8701-BC breast carcinoma cells. Cancer Res 58: 4468-4474, 1998.

18. Shedden K, Xie XT, Chandaroy P, Chang YT and Rosania GR: Expulsion of small molecules in vesicles shed by cancer cells: association with gene expression and chemosensitivity profiles. Cancer Res 63: 4331-4337, 2003.

19. Taverna S, Ghersi G, Ginestra A, et al: Shedding of membrane vesicles mediates fibroblast growth factor-2 release from cells. J Biol Chem 278: 51911-51919, 2003.

20. Janowska-Wieczorek A, Wysoczynski M, Kijowski J, MarquezCurtis L, Machalinski B, Ratajczak J and Ratajczak MZ: Microvesicles derived from activated platelets induce metastasis and angiogenesis in lung cancer. Int J Cancer 113: 752-760, 2005.

21. Marzia M, Sims NA, Voit S, et al: Decreased c-src expression enhances osteoblast differentiation and bone formation. J Cell Biol 151: 311-320, 2000.

22. Albini A, Iwamoto Y, Kleinman HK, Martin GR, Aaronson SA, Kozlowski JM and McEwan RN: A rapid in vitro assay for quantitating the invasive potential of tumor cells. Cancer Res 47: 3239-3245, 1987.

23. Festuccia C, Angelucci A, Gravina GL, Villanova I, Teti A, Albini $\mathrm{A}$ and Bologna M: Osteoblast-derived TGFbeta-1 modulates matrix degrading protease expression and activity in prostate cancer cells. Int J Cancer 86: 888, 2000.

24. Angelucci A, D'Ascenzo S, Festuccia C, Gravina GL, Bologna M, Dolo V and Pavan A: Vesicle-associated urokinase plasminogen activator promotes invasion in prostate cancer cell lines. Clin Exp Metastasis 18: 163-170, 2000.

25. Bjorklund $\mathrm{M}$ and Koivunen E: Gelatinase-mediated migration and invasion of cancer cells. Biochim Biophys Acta 1755: 37-69, 2005.

26. Ree AH, Florenes VA, Berg JP, Maelandsmo GM, Nesland JM and Fodstad O: High levels of messenger RNAs for tissue inhibitors of metalloproteinases (TIMP-1 and TIMP-2) in primary breast carcinomas are associated with development of distant metastases. Clin Cancer Res 3: 1623-1628, 1997.

27. Murphy $\mathrm{G}$ and Willenbrock F: Tissue inhibitors of matrix metalloendopeptidases. Methods Enzymol 248: 496-510, 1995.

28. Duffy MJ: The urokinase plasminogen activator system: role in malignancy. Curr Pharm Des 10: 39-49, 2004. 